\title{
Recent achievements in the management of Raynaud's phenomenon
}

This article was published in the following Dove Press journal:

Vascular Health and Risk Management

27 March 2010

Number of times this article has been viewed

\author{
Magnus Baumhäkel \\ Michael Böhm \\ Klinik für Innere Medizin III, \\ Kardiologie, Angiologie und \\ Internistische Intensivmedizin, \\ Universitätsklinikum des Saarlandes, \\ Homburg/Saar, Germany
}

\begin{abstract}
Raynaud's phenomenon is a clinical disorder with episodic digital ischemic vasospasm triggered by cold- or emotional-stress. It was first mentioned by Maurice Raynaud in 1862 describing "a local asphyxia of the extremities" and was further divided into primary Raynaud's disease and secondary Raynaud's phenomenon, which is often related to connective tissue diseases, but also physical or chemical strain. Though pathophysiology of Raynaud's phenomenon is still poorly understood, systemic and local vascular effects are most likely to be involved in primary Raynaud's disease. In secondary Raynaud's phenomenon additional abnormalities in vascular structure and function may play the major role. Thus, medical treatment of Raynaud's phenomenon remains unsatisfactory, due to limited understanding of pathophysiological mechanisms. This review addresses current evidence for medical treatment of primary and secondary Raynaud's phenomenon with regard to pathophysiological mechanisms as well as future perspectives.
\end{abstract}

Keywords: Raynaud's disease, mechanisms, treatment

\section{Definition and epidemiology}

Raynaud's phenomenon is described as episodic digital ischemic vasospasm triggered by cold- or emotional-stress leading to a pale and cyanotic skin with a postischemic phase of hyperemia; the typical "tricolore phenomenon". ${ }^{1}$ However, because a clear definition and nomenclature of Raynaud's phenomenon is still lacking, we use the terms primary Raynaud's disease and secondary Raynaud's phenomenon throughout this review.

Raynaud's disease was first mentioned by Maurice Raynaud in 1862 describing "a local asphyxia of the extremities" and was further divided into primary Raynaud's disease and secondary Raynaud's phenomenon by Thomas Lewis. ${ }^{1,2}$ Some criteria were proposed to diagnose primary rather than secondary Raynaud's phenomenon. These include typical symptoms of digital vasospasm, absence of peripheral vascular disease, no evidence of tissue necrosis, normal nailfold capillaries, a negative antinuclear antibody test and a normal sedimentation rate. ${ }^{3}$ Moreover, primary Raynaud's disease typically affects all fingers, whereas secondary Raynaud's phenomenon has an asymmetric distribution in most cases.

Primary Raynaud's disease is common, with a prevalence of $3 \%$ to $5 \%$ in the general population, and remains uncomplicated without permanent injury. ${ }^{3}$ The underlying mechanisms of temporary vasospasm are still poorly understood, but are suggested to be purely functional. However, secondary Raynaud's phenomenon occurs in patients with connective tissue disease, but is also driven by physical or chemical strain and
Correspondence: Magnus Baumhäkel

Klinik für Innere Medizin III, Universitätsklinikum des Saarlandes, D-6642I Homburg/Saar, Germany

$\mathrm{Tel}+49684 \mid 1623289$

Fax +49 684I 1623446

Email magnus@baumhaekel.de submit your manuscript $\mid$ www.dovepress.com

Dovepress 
might have a more severe progression with digital necrosis and ulceration leading to disability. ${ }^{4}$

\section{Pathophysiology}

The pathophysiology of Raynaud's phenomenon remains unclear. In contrast to the first description by Maurice Raynaud, vascular rather than neural effects were suggested to play the major role. ${ }^{1}$ Hence, systemic and local vascular effects were most likely to be involved in primary Raynaud's disease, whereas additional abnormalities in vascular structure and vascular function are suggested to cause secondary Raynaud's phenomenon. ${ }^{4}$

\section{Systemic vascular effects}

The key issue of Raynaud's phenomenon is likely to be the imbalance of vasoconstriction and vasodilation due to alterations in neural control of vascular tone and circulating mediators (Figure 1). ${ }^{5}$ These mechanisms are suggested to play a major role in secondary Raynaud's phenomenon due to connective tissue disease as systemic sclerosis. In these patients, circulating levels of endothelin-1, a potent vasoconstrictor, but also involved in fibrosis and structural vascular changes, are significantly increased. ${ }^{6}$ Thus, inhibition of endothelin1 receptors might affect vascular remodeling, proliferation of smooth-muscle cells as well as fibroblasts as a possible treatment target in patients with systemic sclerosis.?

Another key player in vasoconstriction and likely in pathogenesis of Raynaud's phenomenon is angiotensin II. The renin-angiotensin system (RAS) plays a major role in regulation of vascular tone, but also in vascular oxidative stress and remodeling. ${ }^{89}$ The role of the RAS in Raynaud's phenomenon is yet unknown; ${ }^{4}$ however, in patients with cutaneous systemic sclerosis, circulating levels of angiotensin II are increased which might offer a therapeutic approach with angiotensinconverting enzyme (ACE) inhibitors or angiotensin-receptor blockers. ${ }^{10}$

Vasoconstrictive mediators are counterbalanced by vasodilators such as nitric oxide or prostaglandins. Despite vasodilating properties, prostaglandins are suggested to inhibit platelet aggregation as well as chemotaxis of
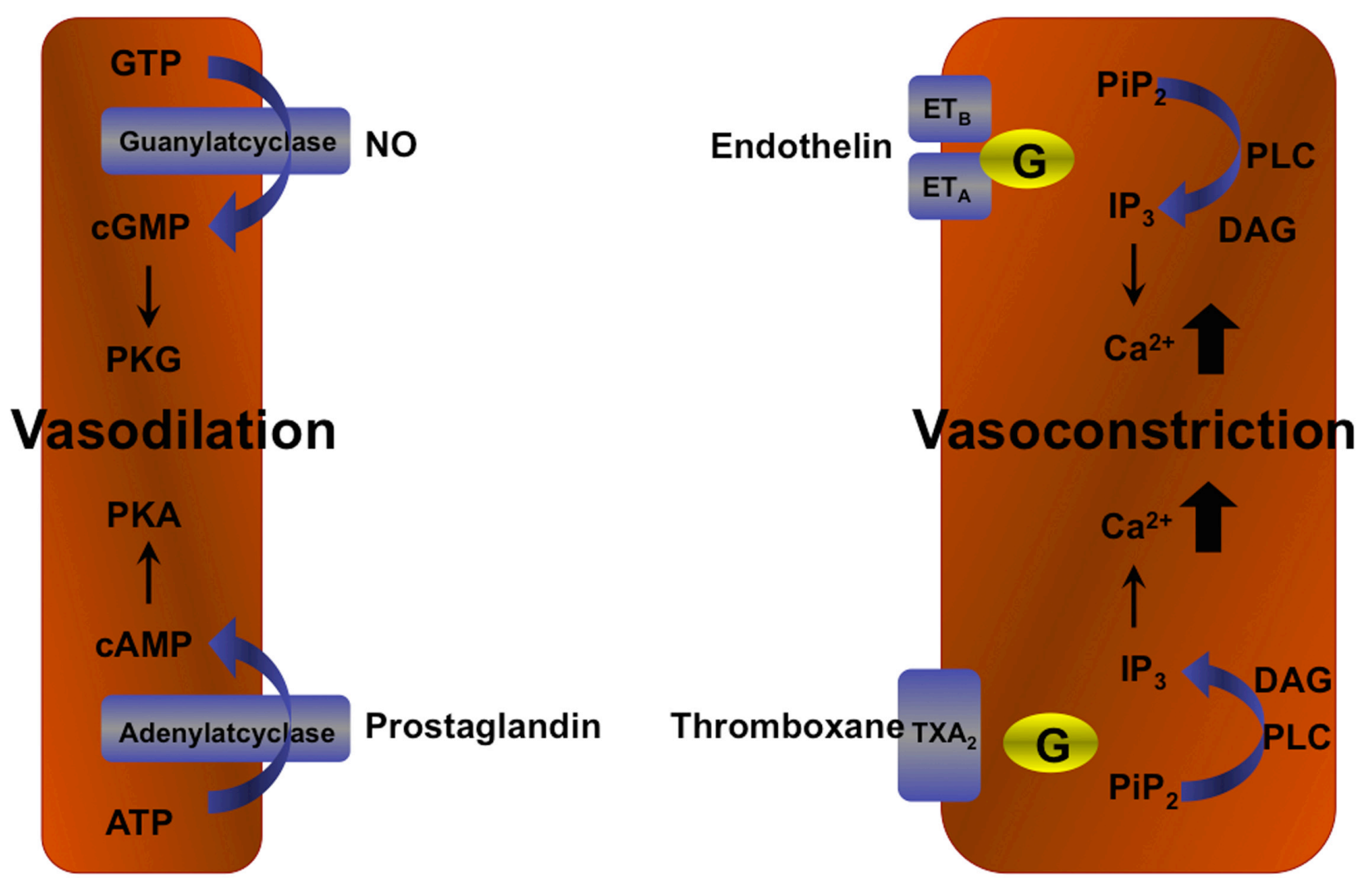

Figure I Imbalance of vasoconstriction and vasodilation in Raynaud's disease.Vasodilators as nitric oxide and prostaglandins act via activation of adenylat- or guanylat-cyclase modulating protein kinase A/G. Vasoconstriction by endothelin or thromboxane is mediated by g-coupled specific receptors and is suggested to be increased in Raynaud's phenomenon.

Abbreviations: cAMP, cyclic adenosine monophosphate; cGMP, cyclic guanylate monophosphate; DAG, diacylglycerol; GTP, guanylate triphosphate; IP, inositol triphosphate; NO, nitric oxide; PIP $_{2}$, phosphatidyl inositol biphosphate; PKA, protein kinase A; PKG, protein kinase G; PLC, phospholipase C. 
leukocytes with consecutive adhesion to the endothelial monolayer. ${ }^{11}$ Moreover, prostaglandins increase fibrinolytic activity, which may additionally play an important role, especially in patients with secondary Raynaud's phenomenon. $^{12}$

Consistently, the vasodilator nitric oxide was found to be decreased more in secondary than primary Raynaud's phenomenon, indicating the crucial role of endothelial function in vascular regulation and hence in Raynaud's phenomenon. ${ }^{6}$ Hence, endothelial synthesis of nitric oxide plays a major role in the pathophysiological mechanisms of Raynaud's phenomenon. Endogenous as well as exogenous nitric oxide acts as a potent vasodilator via activation of guanylate-cyclase with increased levels of cyclic GMP, therefore resulting in dephosphorylation of the myosin light chain of vascular smooth muscle cells with consecutive vasodilation.

\section{Local vascular effects}

In patients with primary Raynaud's disease, vascular response to alpha2-adrenergic agonists, serotonin and angiotensin II was increased during cooling and could be reversed by tyrosine kinase inhibitors. ${ }^{13}$ As a possible mechanism, tyrosine phosphorylation was increased during cold exposure in these patients. Moreover, the alpha2c-adrenoreceptor is known to be important in thermoregulation, with an increased activity after cold exposure. ${ }^{14}$ The underlying pathomechanism is a cold-induced increase of reactive oxygen species activating the rho/rho-kinase-pathway with consecutive translocation of the alpha2c-adrenoreceptor subtype to the cell membrane. ${ }^{15,16}$ Thus, increased expression of this receptor might play a role in primary Raynaud's disease, especially in possible effects of estrogens on receptor expression, reflecting the high prevalence of primary Raynaud's disease in women.

Moreover, regulation of vascular tone not only depends on humoral vasodilating mediators, but also on the release of neuropeptides from corresponding nerve endings. The calcitonin-gene-related peptide, for example, is a potent vasodilator secreted by nerves. In patients with both primary and secondary Raynaud's phenomenon, neuron release was demonstrated to be diminished in skin biopsies. ${ }^{17}$

\section{Treatment}

So far, medical treatment of Raynaud's phenomenon remains unsatisfactory. Nevertheless, recent progress in the understanding of pathophysiological mechanisms has promoted further therapeutic approaches. Some clinical trials have revealed promising results, with different substances acting as vasodilators or inhibitors of increased vasoconstriction, but in general data are limited to small populations enrolled in these trials. Moreover, treatment strongly depends on the etiology of Raynaud's phenomenon as well as on individual symptoms and presence of digital ulcers.

In both primary and secondary Raynaud's phenomenon, lifestyle modifications are ranked first in the treatment algorithm. Proper body insulation, avoidance of cold exposure, stopping possible vasoconstrictive medication and smoking cessation play an important role and might be a sufficient treatment particularly in patients with primary Raynaud's disease. In patients with secondary Raynaud's phenomenon, avoidance of triggering physical or chemical injuries and adequate treatment of the underlying disease are fundamental.

With regard to possible pathophysiological mechanisms of Raynaud's disease and phenomenon, medical treatment is based on regulation of vasomotion by direct vasodilators (nitrates, calcium-channel blockers, prostaglandins, PDE-V inhibitors) and inhibition of vasoconstriction (endothelinreceptor antagonists, angiotensin-receptor blockers, alphareceptor blockers). Moreover, substances that increase endothelial function such as rho-kinase-inhibitors and statins as well as interaction with neural vasoregulation (serotoninreuptake inhibitors) may improve symptoms of Raynaud's disease or phenomenon.

\section{Vasodilators Nitrates}

Nitrates have been used in both primary and secondary Raynaud's phenomenon with different ways of administration: topical with transdermal patches or as different cream or gel formulations as well as in oral applications. Sustained release patches with glyceroltrinitrate were demonstrated to significantly reduce severity $(P<0.05)$ and number $(P<0.05)$ of Raynaud attacks in patients with primary $(\mathrm{n}=21)$ and also in patients with secondary $(\mathrm{n}=21)$ Raynaud's phenomenon. ${ }^{18}$ However, in $80 \%$ of the patients included in these trials, headache limited the use of topical nitrates. Moreover, nitrates had already been shown to improve digital ulcers compared to placebo in the early $1980 \mathrm{~s} .{ }^{19}$ Nevertheless, efficacy as well as duration of possible beneficial effects of nitrates are still not clear in patients with secondary Raynaud's phenomenon, in line with the earliest trials on nitrates in Raynaud's phenomenon of the $1950 \mathrm{~s} .{ }^{20}$ Thus, nitrates might be useful in primary Raynaud's disease only and are highly limited by their frequent side effects, mainly headache and hypotension, irrespective of the way of administration. Interestingly, eight clinical trials are currently investigating the effect of topical 
nitrates on patients with primary and secondary Raynaud's phenomenon. Thus, new data on this class of drug will be obtained in the near future.

\section{Calcium channel blockers}

In general, less cardioselective calcium channel blockers from the dihydropyridine group were suggested to be beneficial in Raynaud's phenomenon and were first choice treatment especially in patients with primary Raynaud's disease. ${ }^{21}$ More cardioselective calcium channel blockers (phenylalkylamine type, benzothiazepine type) were shown to be ineffective in patients with severe Raynaud's phenomenon. ${ }^{22}$

Calcium channel blockers promote relaxation of vascular smooth muscle cells via inhibition of voltage-gated channels, leading to peripheral vasodilation. Especially short-acting substances such as nifedipine can lead to hypotension with consecutive reflex tachycardia, and also headache or flush. ${ }^{23}$ Use of long-acting calcium channel blockers in patients with Raynaud's phenomenon such as felodipine, amlodipine or nitrendipine is controversial. ${ }^{24} \mathrm{~A}$ meta-analysis of calcium channel blockers in patients with primary Raynaud's disease revealed a significant reduction of frequency ( $-2.8 \%$ to $5.0 \%, P=0.01)$ as well as a decrease of severity of Raynaud attacks $(-33 \%, P=0.005) .{ }^{25}$ These results are in line with a previous meta-analysis of studies evaluating the effect of calcium channel blockers in patients with Raynaud's phenomenon due to systemic sclerosis. Within 2 weeks treatment, there was a reduction of 8.3 attacks per week and a $35 \%$ decline in severity of clinical symptoms. ${ }^{26}$ However, improvement of clinical symptoms might be a short-term effect of treatment with calcium channel blockers as beneficial effects can be lost in long-term treatment. ${ }^{24}$ In a head to head comparison of $40 \mathrm{mg}$ nifedipine with intravenous iloprost in patients with secondary Raynaud's phenomenon, there was no effect of treatment with nifedipine after 1 year. ${ }^{27}$

In clinical practice, calcium channel blockers are the first choice in primary Raynaud's disease and have been suggested for testing in secondary Raynaud's phenomenon. Treatment should start with low dosages and should be titrated with regard to individual symptoms. Recommended doses are nifedipine 10 to $30 \mathrm{mg} 3$ times daily or amlodipine 5 to $20 \mathrm{mg}$ once daily. In patients with a CREST-syndrome, calcium channel blockers can reduce sphincter tone in the lower esophagus, in these patients calcium channel blockers should be used with caution.

\section{Prostaglandins}

Prostaglandins have vasodilatory properties, antiproliferative effects on vasculature and inhibit platelet aggregation.
In the treatment of primary and secondary Raynaud's phenomenon, intravenous administration of prostaglandin E1 as well as iloprost were shown to be beneficial. ${ }^{28}$ In patients with secondary Raynaud's phenomenon, treatment with iloprost 6 weekly significantly decreased the Raynaud's score compared to the calcium channel blocker nifedipin $(P=0.002) .{ }^{27}$ Moreover, in a multicenter trial with 131 patients with systemic sclerosis, iloprost improved Raynaud's score (decrease of $39 \%$ vs $22 \%, P=0.005$ ) as well as healing of digital ulcers in comparison to placebo. ${ }^{29}$ However, the role of oral or inhaled preparations of prostaglandins is yet not clear and should be evaluated in further clinical trials.

Side effects of prostaglandins were dose-dependent and a result of peripheral vasodilation with headache, flush and nausea. In patients with congestive heart failure, prostaglandins may lead to pulmonary edema; hence outpatient treatment is not recommended in these patients. Moreover, low-dose treatment with prostaglandins $(0.5 \mathrm{ng} / \mathrm{kg}$ body weight per min ilpoprost) is suggested to be equally effective to high-dose treatment $(2.0 \mathrm{ng} / \mathrm{kg}$ body weight per min ilpoprost) in patients with systemic sclerosis. ${ }^{30}$

\section{Phosphodiesterase inhibitors}

Phosphodiesterase type V (PDE-V) inhibitors mediate vasodilatory effects via accumulation of cyclic guanosine monophosphate in vascular smooth muscle cells and were indicated in treatment of erectile dysfunction and more recently in pulmonary hypertension. ${ }^{31}$ In patients with pulmonary hypertension due to connective tissue disease, medical treatment with PDE-V inhibitors was reported to improve symptoms of secondary Raynaud's phenomenon. Consistently, PDE-V inhibitors were demonstrated to have beneficial effects in primary and secondary Raynaud's phenomenon in several studies and case reports. In a single-center trial with 16 patients with secondary Raynaud's phenomenon resistant to vasodilatory treatment, 4-week treatment with $50 \mathrm{mg}$ sildenafil twice daily reduced number of attacks (35 \pm 14 vs $52 \pm 18, P=0.0064)$ and mean Raynaud's condition score $(2.2 \pm 0.4$ vs $3.0 \pm 0.5, P=0.0386) .{ }^{32}$ Moreover, capillary blood flow improved significantly $(P=0.0004)$ compared to placebo. These data were consistent with two case series in which sildenafil reduced frequency and severity of attacks in patients with secondary Raynaud's phenomenon. ${ }^{33,34}$

In a case-report, tadalafil, another PDE-V inhibitor, was reported to be beneficial in a patient with secondary Raynaud's phenomenon not responding to sildenafil. ${ }^{35}$ Recent data are in line with this observation. In patients with 
systemic sclerosis, plasma endothelin-1 levels were reduced by daily treatment with tadalafil. ${ }^{36}$ However, in a randomized, cross-over trial comparing tadalafil with placebo in patients with Raynaud's phenomenon and systemic sclerosis, there was no significant difference in number, severity and duration of Raynaud's attacks. ${ }^{37}$

PDE-V inhibitors are one of the most promising class of substances for treatment of Raynaud's phenomenon, but more data are needed. A current trial evaluating a novel PDEV-inhibitor (SLx-2101) in patients with secondary Raynaud's phenomenon has been completed, and the results are expected to be published in early in 2010. At the moment, sildenafil shows best evidence for beneficial effects.

\section{Inhibition of vasoconstriction}

\section{Endothelin receptor antagonists}

Endothelin-1 is a potent vasoconstrictor, but is also involved in vascular remodeling and local fibrosis, especially in patients with secondary Raynaud's phenomenon. ${ }^{7}$ In patients with systemic sclerosis, plasma concentrations of endothelin-1 were reported to be significantly increased, with enhanced proliferation and consecutive hypertrophy of vascular smooth muscle cells and fibroblasts. ${ }^{38}$ Thus, inhibition of endothelin-1 exerts chronic effects on proliferation and vascular structure rather than acute effects on vasomotion. Bosentan is a competitive antagonist of both endothelin receptor subtypes A and B, with a higher affinity to the first receptor. In the RAPIDS-1 trial (Randomized Placebo-controlled Investigation of Digital Ulcers in Scleroderma) bosentan was evaluated in 122 patients with systemic sclerosis. During the treatment period of 4 months, bostentan reduced onset of new digital ulcers by $48 \%$ in comparison to placebo. ${ }^{39}$ However, the second endpoint of time to healing of digital ulcers did not differ significantly between the two treatment arms. The RAPIDS-2 trial included 188 patients with secondary Raynaud's phenomenon treated with bosentan or placebo for 20 to 32 weeks. Again, number of new digital ulcers decreased significantly with bosentan (bosentan $1.9 \pm 0.2$ vs placebo $2.7 \pm 0.3, P=0.035$ ). Based on these results, bosentan was marketed in the European Union in 2007, being indicated for the reduction of onset of digital ulcers in patients with systemic sclerosis. Adverse effects of bosentan were particularly increased hepatic aminotransferase levels, which were dose-dependent and might occur in about $10 \%$ of patients treated.

\section{Angiotensin receptor blockers}

ACE inhibitors as well as ARBs were demonstrated to be beneficial in cardiovascular risk patients. ${ }^{40} \mathrm{ACE}$ inhibitors and ARBs may also provide improvement in patients with Raynaud's phenomenon, although no definite evidence exists to suggest that they are superior to commonly used vasodilating substances. ${ }^{41}$ Large, randomized, controlled trials are needed to compare the effects of ACE inhibitors and ARBs with conventional vasodilatory treatment. ${ }^{42}$ In one small trial including patients with primary $(n=25)$ and secondary ( $n=27$ ) Raynaud's phenomenon, losartan was demonstrated to decrease frequency of attacks significantly compared to nifedipine $(P=0.018)$ after treatment for 15 weeks. Additionally, symptoms improved with losartan $(P<0.05) .{ }^{43}$ Beneficial effects were more pronounced in the subgroup of patients with primary Raynaud's disease. Nevertheless, further trials are needed to judge the role of inhibitors of the RAS in patients with Raynaud's phenomenon.

\section{Alpha-adrenoreceptor blockers}

Alpha-adrenoreceptors play an important role in sympathetic nervous regulation of vascular tone, but also in skin temperature regulation. ${ }^{41}$ Prazosin inhibits the alpha- 1 postsynaptic adrenoreceptor with consecutive peripheral vasodilation. In a meta-analysis including 2 trials with a total of 40 patients with secondary Raynaud's phenomenon due to systemic sclerosis, prazosin significantly decreased severity and frequency of Raynaud's attacks. ${ }^{44}$ Despite beneficial effects, several side effects as nausea, dizziness, headache, palpitations and hypotension limit the use of this substance.

Pathophysiological mechanisms and especially the role in thermoregulation of the alpha2c-adrenoreceptor subtype have been described above. In a small trial with 13 patients with systemic sclerosis and consecutive Raynaud's phenomenon, a specific alpha2c-adrenoreceptor subtype blocker decreased time to recovery of skin temperature after cold exposure significantly (50\% of recovery within 5.8 vs $10.0 \mathrm{~min}, P=0.02) .{ }^{45}$ Moreover, digital blood flow increased compared to placebo. These data were promising, even for low frequency of side effects, but further studies with more relevant endpoints such as frequency and severity of attacks are needed.

\section{Improvement of endothelial function \\ Rho-kinase inhibitors}

Rho-kinase is involved in cold-induced modulation of expression or rather translocation of the alpha2c-adrenoreceptor subtype to the plasma membrane. Moreover, rho-kinase is a key mediator of pleiotropic effects of statins, with beneficial effects on endothelial function and development 
of atherosclerosis. ${ }^{46}$ Thus, overactivity of rho-kinase was described in several vascular disorders as cerebral ischemia, and also coronary vasospasm. ${ }^{47}$ Fasudil is a potent inhibitor of rho-kinase and was demonstrated to have beneficial effects in vasospastic angina. ${ }^{48}$ Recently, fasudil was shown to increase nitric oxide-dependent forearm blood flow and to prevent aortic vasoconstriction in an animal model. ${ }^{49,50}$ A phase III trial with 24 patients with secondary Raynaud's phenomenon is currently being performed with fasudil at the Johns Hopkins University (clinicaltrials.gov identifier: NCT00498615). Results may be available in 2010.

\section{Statins}

Statins display pleiotropic effects on endothelial function, which may be beneficial also in Raynaud's phenomenon. In patients with secondary Raynaud's phenomenon due to systemic sclerosis, $40 \mathrm{mg}$ of atorvastatin $(n=56)$ or placebo $(n=28)$ was added to ongoing vasodilatory treatment. ${ }^{51}$ The overall number of digital ulcers was significantly reduced in the statin group, with a consecutive improvement of quality of life. Another openlabel study is currently investigating the effects of atorvastatin on Raynaud's phenomenon in patients with systemic lupus erythematodes. Thus, HMG-CoA-reductase inhibitors were suggested to be a promising therapeutic option, especially in addition to existing vasodilatory treatment, but more data are necessary to judge the definite role of this class of drugs.

\section{Neural vasoregulation \\ Serotonin reuptake inhibitors}

Digital vasomotion may in part depend on serotonin reuptake in the central nervous system. Moreover, serotonin reuptake may interfere with platelets, but the overall role in Raynaud's phenomenon remains uncertain. In patients with primary Raynaud's disease, 6 weeks' treatment with the selective serotonin reuptake inhibitor fluoxetine $(20 \mathrm{mg})$ improved severity and frequency of attacks compared to nifedipine (40 mg) significantly $(P<0.001)$, but effects were less pronounced in secondary Raynaud's phenomenon. ${ }^{52}$ Consistently, a metaanalysis of the serotonin-reuptake inhibitor ketanserin demonstrated no beneficial effects in secondary Raynaud's phenomenon due to systemic sclerosis. ${ }^{53}$ Currently there are insufficient data to support the routine use of this substance in Raynaud's phenomenon.

\section{Treatment algorithm}

Raynaud's phenomenon is a complex disease with several factors suggested to be involved in pathological vasomotion and also vascular remodeling. Thus, the decision on therapeutic approach has to be taken on a case by case basis. In patients with primary Raynaud's disease, lifestyle modifications eclipse medical treatment. Avoidance of cold exposure and protection are most important in these patients. Moreover, smoking cessation is recommended, despite unclear evidence of an association with Raynaud's phenomenon. ${ }^{54}$ If severity of symptoms requires medical treatment despite lifestyle changes, topical nitrates or low-dose treatment with calcium-channel blockers are recommended.

In patients with secondary Raynaud's phenomenon, treatment of the underlying disease is crucial. In addition to lifestyle changes, calcium-channel blockers are also suggested to be the first-line treatment in these patients. Patients who do not respond or do not tolerate calcium-channel blockers may use other vasodilatory substances alone or in combination, whereas data from clinical trials on combined treatment in Raynaud's phenomenon are not available. A possible treatment algorithm suggested by the authors is depicted in Figure 2. Further trials of several different substances are expected within the next few years. PDE-V inhibitors, rho-kinase inhibitors and endothelin-receptor antagonists especially seem to be most promising for treatment of both primary and secondary Raynaud's phenomenon.

Patients who develop severe digital ischemia including ulcerations often require hospitalization with application of intravenous prostaglandins. PDE-V inhibitors may also be used for treatment of digital ulcers, but their application is still "off-label". Patients with systemic sclerosis and history of digital ulcers may be treated with bosentan for prevention of onset of new ulcers.

\section{Future perspective}

Diagnosis and treatment of Raynaud's phenomenon is a major challenge in view of the wide variety of symptoms and pathophysiological mechanisms involved, especially in secondary Raynaud's phenomenon due to connective tissue diseases. Pathological vascular conditions, but also structural abnormalities are suggested to play the major role in pathophysiology of Raynaud's phenomenon, but are still poorly understood. The key factors influencing these mechanisms are endothelin-1 and endothelial dysfunction, with consecutive decreased nitric oxide synthesis being responsible for the imbalance of vasoconstriction and vasodilation. Hence, substances inhibiting vascular effects of endothelin-1 as well as improving endothelial function or enhancing nitric oxide-related effects as PDE-V inhibitors are suggested to be the most promising agents for future treatment and research, especially in secondary Raynaud's phenomenon. 


Primary Raynaud's disease
avoidance of cold exposure
sufficent protection
smoking cessation
avoidance of
sympathomimetic drugs
$\mid$ vasodilatory treatment
topical nitrates
long acting CCB

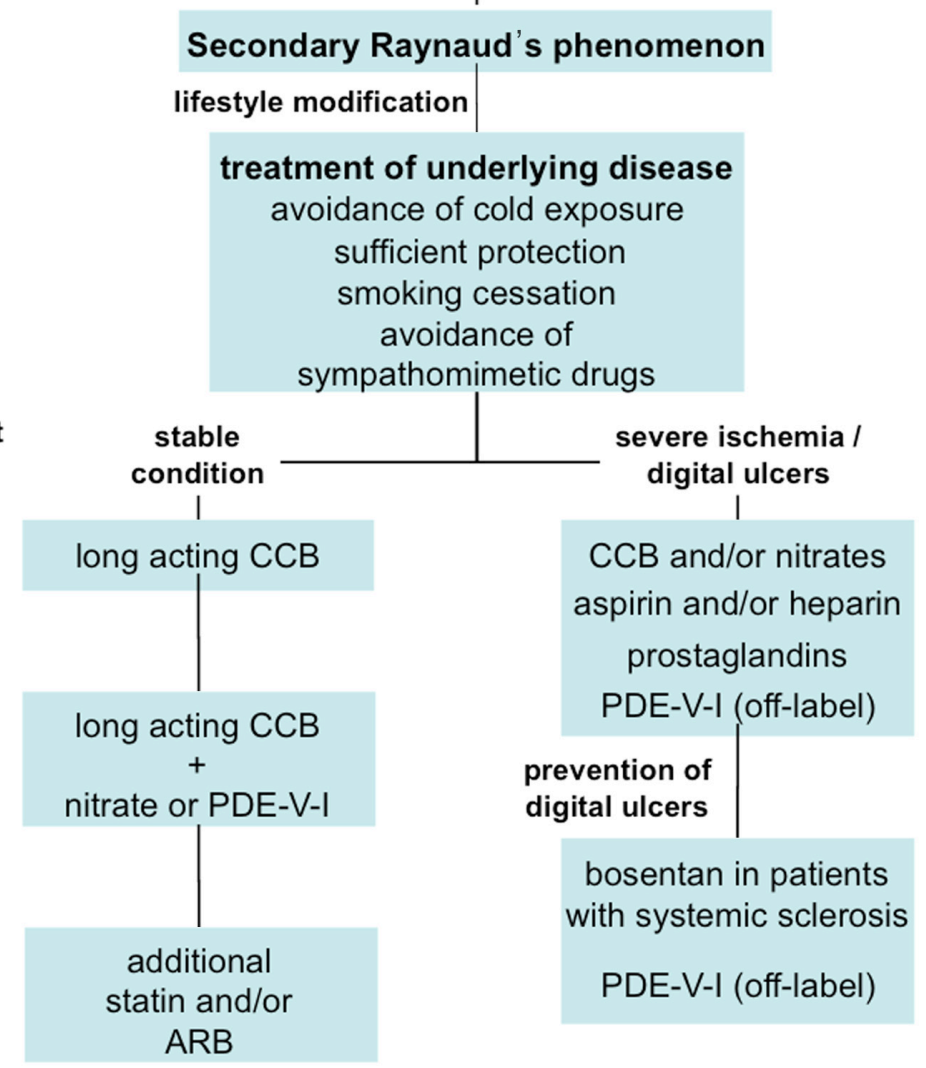

Secondary Raynaud's phenomenon

treatment of underlying disease

voidance of cold exposure

sufficient protection

moking cessation

avoidance of

sympathomimetic drugs

Figure 2 Treatment algorithm for Raynaud's phenomenon.

\section{Disclosures}

The authors declare no conflicts of interest.

\section{References}

1. Raynaud M. Local Asphyxia and Symmetrical Gangrene of the Extremities. London: New Sydenham Society. 1862.

2. Lewis T. Experiments relating to the peripheral mechanisms involved in spasmodic arrest of the circulation in the fingers, a variety of Raynaud's disease. Heart. 1929;15:7-101.

3. LeRoy EC, Medsger TA Jr. Raynaud's phenomenon: a proposal for classification. Clin Exp Rheumatol. 1992;10(5):485-488.

4. Bakst R, Merola JF, Franks AG Jr, Sanchez M. Raynaud's phenomenon: pathogenesis and management. J Am Acad Dermatol. 2008;59(4): 633-653.

5. Kaheleh B, Matucci-Cerinic M. Raynaud's phenomenon and scleroderma. Dysregulated neuroendothelial control of vascular tone. Arthritis Rheum. 1995;38:1-4.

6. Rajagopalan S, Pfenninger D, Kehrer C, et al. Increased asymmetric dimethylarginine and endothelin 1 levels in secondary Raynaud's phenomenon: implications for vascular dysfunction and progression of disease. Arthritis Rheum. 2003;48(7):1992-2000.

7. Kirchengast M, Munter K. Endothelin-1 and endothelin receptor antagonists in cardiovascular remodeling. Proc Soc Exp Biol Med. 1999;221(4):312-325.

8. Baumhakel M, Custodis F, Schlimmer N, Laufs U, Bohm M. Improvement of endothelial function of the corpus cavernosum in apolipoprotein E knockout mice treated with irbesartan. J Pharmacol Exp Ther. 2008;327(3):692-698.

9. Friedrich EB, Teo KK, Bohm M. ACE inhibition in secondary prevention: are the results controversial? Clin Res Cardiol. 2006;95(2):61-67.
10. Kawaguchi Y, Takagi K, Hara M, et al. Angiotensin II in the lesional skin of systemic sclerosis patients contributes to tissue fibrosis via angiotensin II type 1 receptors. Arthritis Rheum. 2004;50(1):216-226.

11. Yardumian DA, Mackie IJ, Brennan EC, Bull H, Machin SJ. Platelet function studies during and after infusions of ZK 36374, a stable prostacyclin analogue, to healthy volunteers. Haemostasis. 1986;16(1):20-26.

12. Bertele V, Mussoni L, del Rosso G, et al. Defective fibrinolytic response in atherosclerotic patients - effect of iloprost and its possible mechanism of action. Thromb Haemost. 1988;60(2):141-144.

13. Furspan PB, Chatterjee S, Freedman RR. Increased tyrosine phosphorylation mediates the cooling-induced contraction and increased vascular reactivity of Raynaud's disease. Arthritis Rheum. 2004;50(5):1578-1585.

14. Chotani MA, Flavahan S, Mitra S, Daunt D, Flavahan NA. Silent alpha(2C)-adrenergic receptors enable cold-induced vasoconstriction in cutaneous arteries. Am J Physiol. 2000;278(4):H1075-H1083.

15. Bailey SR, Eid AH, Mitra S, Flavahan S, Flavahan NA. Rho kinase mediates cold-induced constriction of cutaneous arteries: role of alpha2C-adrenoceptor translocation. Circ Res. 2004;94(10): $1367-1374$.

16. Bailey SR, Mitra S, Flavahan S, Flavahan NA. Reactive oxygen species from smooth muscle mitochondria initiate cold-induced constriction of cutaneous arteries. Am J Physiol. 2005;289(1):H243-H250.

17. Bunker CB, Terenghi G, Springall DR, Polak JM, Dowd PM. Deficiency of calcitonin gene-related peptide in Raynaud's phenomenon. Lancet. 1990;336(8730):1530-1533.

18. Teh LS, Manning J, Moore T, Tully MP, O’Reilly D, Jayson MI. Sustained-release transdermal glyceryl trinitrate patches as a treatment for primary and secondary Raynaud's phenomenon. Br J Rheumatol. 1995;34(7):636-641. 
19. Franks AG Jr. Topical glyceryl trinitrate as adjunctive treatment in Raynaud's disease. Lancet. 1982;1(8263):76-77.

20. Kleckner M Jr, Allen EV, Wakim KG. The effect of local application of glyceryl trinitrate (nitroglycerine) on Raynaud's disease and Raynaud's phenomenon; studies on blood flow and clinical manifestations. Circulation. 1951;3(5):681-689.

21. Stosic-Grujicic SD, Maksimovic DD, Stojkovic MB, Lukic ML. Pentoxifylline prevents autoimmune mediated inflammation in low dose streptozotocin induced diabetes. Dev Immunol. 2001;8(3-4):213-221.

22. Kinney EL, Nicholas GG, Gallo J, Pontoriero C, Zelis R. The treatment of severe Raynaud's phenomenon with verapamil. J Clin Pharmacol. 1982;22(1):74-76.

23. Abernethy DR, Schwartz JB. Calcium-antagonist drugs. N Engl J Med. 1999;341(19):1447-1457.

24. Opie LH, Yusuf S, Kubler W. Current status of safety and efficacy of calcium channel blockers in cardiovascular diseases: a critical analysis based on 100 studies. Prog Cardiovasc Dis. 2000;43(2):171-196.

25. Thompson AE, Pope JE. Calcium channel blockers for primary Raynaud's phenomenon: a meta-analysis. Rheumatology (Oxford). 2005;44(2): 145-150.

26. Thompson AE, Shea B, Welch V, Fenlon D, Pope JE. Calcium-channel blockers for Raynaud's phenomenon in systemic sclerosis. Arthritis Rheum. 2001;44(8):1841-1847.

27. Scorza R, Caronni M, Mascagni B, et al. Effects of long-term cyclic iloprost therapy in systemic sclerosis with Raynaud's phenomenon. A randomized, controlled study. Clin Exp Rheumatol. 2001;19(5):503-508.

28. Stosic-Grujicic S, Maksimovic D, Badovinac V, et al. Antidiabetogenic effect of pentoxifylline is associated with systemic and target tissue modulation of cytokines and nitric oxide production. $J$ Autoimmun. 2001;16(1):47-58.

29. Wigley FM, Wise RA, Seibold JR, et al. Intravenous iloprost infusion in patients with Raynaud phenomenon secondary to systemic sclerosis. A multicenter, placebo-controlled, double-blind study. Ann Intern Med. 1994;120(3):199-206.

30. Kawald A, Burmester GR, Huscher D, Sunderkotter C, Riemekasten G. Low versus high-dose iloprost therapy over 21 days in patients with secondary Raynaud's phenomenon and systemic sclerosis: a randomized, open, single-center study. J Rheumatol. 2008;35(9):1830-1837.

31. Wilkins MR, Paul GA, Strange JW, et al. Sildenafil versus Endothelin Receptor Antagonist for Pulmonary Hypertension (SERAPH) study. Am J Resp Crit Care Med. 2005;171(11):1292-1297.

32. Fries R, Shariat K, von Wilmowsky H, Bohm M. Sildenafil in the treatment of Raynaud's phenomenon resistant to vasodilatory therapy. Circulation. 2005;112(19):2980-2985.

33. Lichtenstein JR. Use of sildenafil citrate in Raynaud's phenomenon: comment on the article by Thompson et al. Arthritis Rheum. 2003;48(1):282-283; author reply 3.

34. Kumana CR, Cheung GT, Lau CS. Severe digital ischaemia treated with phosphodiesterase inhibitors. Ann Rheum Dis. 2004;63(11): 1522-1524.

35. Baumhaekel M, Scheffler P, Boehm M. Use of tadalafil in a patient with a secondary Raynaud's phenomenon not responding to sildenafil. Microvasc Res. 2005;69(3):178-179.

36. Rosato E, Letizia C, Proietti M, et al. Plasma adrenomedullin and endothelin-1 levels are reduced and Raynaud's phenomenon improved by daily tadalafil administration in male patients with systemic sclerosis. J Biol Regul Homeost Agents. 2009;23(1):23-29.

Vascular Health and Risk Management

\section{Publish your work in this journal}

Vascular Health and Risk Management is an international, peerreviewed journal of therapeutics and risk management, focusing on concise rapid reporting of clinical studies on the processes involved in the maintenance of vascular health; the monitoring, prevention and treatment of vascular disease and its sequelae; and the involvement of
37. Schiopu E, Hsu VM, Impens AJ, et al. Randomized placebo-controlled crossover trial of tadalafil in Raynaud's phenomenon secondary to systemic sclerosis. J Rheumatol. 2009;36(10):2264-2268.

38. Morelli S, Ferri C, Polettini E, et al. Plasma endothelin-1 levels, pulmonary hypertension and lung fibrosis in patients with systemic sclerosis. Am J Med. 1995;99(3):255-260.

39. Korn JH, Mayes M, Matucci Cerinic M, et al. Digital ulcers in systemic sclerosis: prevention by treatment with bosentan, an oral endothelin receptor antagonist. Arthritis Rheum. 2004;50(12):3985-3993.

40. Werner C, Baumhakel M, Teo KK, et al. RAS blockade with ARB and ACE inhibitors: current perspective on rationale and patient selection. Clin Res Cardiol. 2008;97(7):418-431.

41. Garcia-Carrasco M, Jimenez-Hernandez M, Escarcega RO, et al. Treatment of Raynaud's phenomenon. Autoimmunity reviews. 2008;8(1): 62-68.

42. Wood HM, Ernst ME. Renin-angiotensin system mediators and Raynaud's phenomenon. Ann Pharmacother. 2006;40(11):1998-2002.

43. Dziadzio M, Denton CP, Smith R, et al. Losartan therapy for Raynaud's phenomenon and scleroderma: clinical and biochemical findings in a fifteen-week, randomized, parallel-group, controlled trial. Arthritis Rheum. 1999;42(12):2646-2655.

44. Pope J, Fenlon D, Thompson A, et al. Prazosin for Raynaud's phenomenon in progressive systemic sclerosis. Cochrane Database Syst Rev. 2000;(2):CD000956.

45. Wise RA, Wigley FM, White B, et al. Efficacy and tolerability of a selective alpha(2C)-adrenergic receptor blocker in recovery from cold-induced vasospasm in scleroderma patients: a single-center, double-blind, placebo-controlled, randomized crossover study. Arthritis Rheum. 2004;50(12):3994-4001.

46. Laufs U, La Fata V, Plutzky J, Liao JK. Upregulation of endothelial nitric oxide synthase by HMG CoA reductase inhibitors. Circulation. 1998;97(12):1129-1135.

47. Rikitake Y, Liao JK. ROCKs as therapeutic targets in cardiovascular diseases. Exp Rev Cardiovasc Ther. 2005;3(3):441-451.

48. Masumoto A, Mohri M, Shimokawa H, Urakami L, Usui M, Takeshita A. Suppression of coronary artery spasm by the Rho-kinase inhibitor fasudil in patients with vasospastic angina. Circulation. 2002;105(13):1545-1547.

49. Bussemaker E, Herbrig K, Pistrosch F, Palm C, Passauer J. Role of rho-kinase in the regulation of vascular tone in hypertensive renal transplant recipients. Atherosclerosis. 2009;207(2):567-572.

50. Chan CK, Mak JC, Man RY, Vanhoutte PM. Rho kinase inhibitors prevent endothelium-dependent contractions in the rat aorta. $J$ Pharmacol Exp Ther. 2009;329(2):820-826.

51. Abou-Raya A, Abou-Raya S, Helmii M. Statins: potentially useful in therapy of systemic sclerosis-related Raynaud's phenomenon and digital ulcers. J Rheumatol. 2008;35(9):1801-1808.

52. Coleiro B, Marshall SE, Denton CP, et al. Treatment of Raynaud's phenomenon with the selective serotonin reuptake inhibitor fluoxetine. Rheumatology (Oxford). 2001;40(9):1038-1043.

53. Pope J, Fenlon D, Thompson A, et al. Ketanserin for Raynaud's phenomenon in progressive systemic sclerosis. Cochrane Database Syst Rev. 2000;(2):CD000954.

54. Herrick AL. Pathogenesis of Raynaud's phenomenon. Rheumatology (Oxford). 2005;44(5):587-596.

metabolic disorders, particularly diabetes. This journal is indexed on PubMed Central and MedLine. The manuscript management system is completely online and includes a very quick and fair peer-review system, which is all easy to use. Visit http://www.dovepress.com/ testimonials.php to read real quotes from published authors. 